\title{
Periodicals and the Liberal Arts College Library
}

College libraries are encountering increasing difficulties in meeting their readers' needs for access to periodical literature. Analysis of the periodical holdings of the ten liberal arts college libraries that created the ACM Periodical Bank shows that the "basic list" of periodicals that every such library holds is very short and that these titles are the ones from which the member libraries most frequently requested photocopies. The study also suggests that little or no use is being made of most of the periodicals on college library holdings lists.

NE OF THE MOST DIFFICULT TASKS faced by the college librarian is that of providing faculty members and students with access to the periodical literature that they seek. Rapidly rising subscription costs and the increasing numbers of periodicals being published are making the task more difficult each year. A major difficulty is that most college librarians have very meager information on the use being made of the periodicals that they are being asked to acquire. As a consequence, most such libraries are spending thousands of dollars each year on periodicals that no one reads, and still the needs of their readers for access to periodical literature are not being fully met. Studies of the periodical holdings of the liberal arts colleges that created the Periodical Bank of the

Blair Stewart is research director of the Periodical Bank of the Associated Colleges of the Midwest. The investigation reported here was supported in part by the U.S. Office of Education; however, the opinions expressed do not necessarily reflect the position or policy of that agency, nor should official endorsement by the office be inferred.
Associated Colleges of the Midwest and of the use they have made of the Periodical Bank, provide some useful insights into periodical use patterns and their relation to the periodical holdings of liberal arts college libraries.

The creation of the Periodical Bank was based on a number of assumptions. The member colleges of ACM are relatively small liberal arts colleges with similar curricula and, presumably, very similar needs for library services. It was assumed that these needs included in each library current subscriptions and back files for a basic core of something like 500 periodicals. In addition, faculty members and students needed ready access to a much larger list of less frequently used periodicals, a list so large that only the most affluent college library could hope to hold a substantial part of it. Ready access meant a more rapid service than could be provided by the usual interlibrary loan services, many of which were not available in response to undergraduate student requests. It was proposed that such a service be provided by establishing a central periodical library which would sub- 
scribe to, and maintain back files of, the less used periodicals not included in the basic list. The member college libraries would be connected with the central library by teletypewriter, and photocopies of desired articles would be promptly produced and sent to the ordering library by first class mail.

Inherent in the procedures adopted was the assumption that the role of a college library's service in the field of periodicals is to meet the expressed needs of its readers. Substantial sums are spent each year by every library in acquiring, processing, binding, and storing the periodicals designed to meet these needs. Some portion of this expenditure is for periodicals that are not used. The omniscient college librarian would presumably not acquire such periodicals, but would only acquire those periodicals, the use of which justified the cost and effort involved in obtaining and retaining them. It was assumed that it was not appropriate to levy a charge on the reader when the librarian had not been omniscient and had acquired periodicals that no one read, but could not provide direct access to some periodicals that were needed. Therefore, no charge was to be made for photocopies of articles to be supplied by the central library. The Periodical Bank service was to be fully incorporated into the libraries' normal provision of access to periodical literature, although screening procedures might be necessary to avoid abuse of the opportunity to obtain free photocopies of periodical articles.

The Periodical Bank was created in 1968 by the ten original members of the Associated Colleges of the Midwest: Beloit, Carleton, Coe, Cornell, Grinnell, Knox, Lawrence, Monmouth, Ripon, and St. Olaf. A central periodical collction was established with holdings of some 1,600 periodicals. Soon after the bank began operations in 1969, arrangements were made to use the periodical collections of major libraries in the Chicago area to supplement the central collection. The cooperating libraries are the John Crerar Library, the Newberry Library, and the libraries of the University of Chicago, of the University of Illinois-Chicago Circle, of Northwestern University, and of the Central Serials Service of the North Suburban Library System. After approximately three years of service to the original member libraries, the bank began to offer its services to other academic and public libraries as associate members, but this study is confined to the periodical holdings of the ten original libraries and the service to them by the bank from September 1, 1969, to June 30, 1972.

\section{Member Library Periodical Holdings}

Union lists of holdings of the ten member libraries were produced by the Periodical Bank in 1970 and 1971. Analysis of the union list as of June 1971 resulted in two surprises that indicated that some preconceptions held by the creators of the bank were invalid. It had been assumed that the lists of the periodical holdings of the member libraries were pretty much alike and that there was a basic list of perhaps as many as 500 titles that all of the libraries would have. As shown in Table 1, the "basic list" in fact consisted of only eighty-five titles. But eighty-five titles on ten holdings lists do not mean that all ten libraries were currently subscribing to these eighty-five periodicals. Included in the eighty-five was the Kenyon Review, which ceased publication in 1970 . In addition, subscriptions to nine of these periodicals had been dropped by one library, and two of them had been dropped by two of the libraries. There were, therefore, only seventy-three periodicals to which all ten of the libraries were subscribing in 1971.

The second unexpected discovery was the large number of periodicals held by only one library-no less than $2,347 \mathrm{ti}$ - 
TABLE 1

Periodical Titles Held by Member Libraries, June 1971, Classified by the Number of Libraries Holding the Title

\begin{tabular}{cc}
\hline \hline $\begin{array}{c}\text { Number of Libraries } \\
\text { Holding }\end{array}$ & Title \\
\hline 1 & 2,347 \\
2 & 624 \\
3 & 315 \\
4 & 207 \\
5 & 145 \\
6 & 127 \\
7 & 76 \\
8 & 89 \\
9 & 91 \\
10 & 85 \\
TOTAL & 4,106 \\
\hline
\end{tabular}

tles. Here again it is necessary to examine the nature of the titles held. It turns out that 350 of them were files of periodicals that had ceased publication, and 755 were remnants of currently published periodicals to which subscriptions had been dropped. This reduces the number of periodicals to which only one library was subscribing to 1,242 . Even this seems a very large number when compared with the 73 titles to which all ten libraries were subscribing.

The 755 back files of periodicals to which subscriptions had been dropped and which were unique to a single library were over half of the 1,367 dropped subscriptions shown on the union lists of holdings. The existence of so many remnants of currently published periodicals raises a number of questions about periodical acquisition and retention policies. There are, of course, a number of different reasons for dropping subscriptions. The subscription rate may have become so high that continued subscription could not be justified, even for a periodical that was sometimes used. Shifts in curriculum or faculty interests may reduce or eliminate entirely the demand for a once useful periodical, or it may be decided that the original subscription was a mistake. Where the periodical has continuing usefulness, the retention of the truncated back file may be justified. Where it is not being used, there is normally little excuse for its retention in a liberal arts college library. The back file may be salable, in which case a better use can presumably be found for the money it will bring. Loading the shelves with unused back files is, in any case, an expensive procedure.

The member libraries seem to have had a wide range of policies with respect to ceased titles and dropped subscriptions. At one extreme were two libraries that had over 90 percent of their holdings in the form of periodicals to which they were currently subscribing. At the other extreme were two libraries that were subscribing to less than 64 percent of the titles on their holdings lists. In the former case the dropped or ceased periodicals retained were presumably judged to be useful. Where large numbers of remnants from dropped subscriptions were retained, however, it may be assumed that they include substantial numbers of periodicals that had not been useful enough to warrant continued subscription; in which case a partial back file would be even less useful. On this assumption it is of interest to look at the distribution of dropped titles in terms of the number of libraries holding the periodical. This is done in Table 2.

This table shows the extreme diversity in the holdings of the ten libraries. Well over half of the 3,553 active titles are uniquely held, and there are only 450 titles held by a majority of the libraries. It also shows that those libraries that have continued to hold back files of periodicals to which they once subscribed have most frequently been dissatisfied with periodicals to which they were the only subscriber among the ten libraries. As stated above, more than half of the subscriptions dropped were to periodicals now held by only one library. As the number of libraries holding a title increases, the proportion of 
dropped subscriptions falls. Only 4.3 percent of the subscriptions to titles now held by six or more libraries have been dropped, while the proportion is 23.3 percent for titles held by five or less libraries. To some extent this contrast is an artifact of the policy of some libraries of disposing of many of the titles to which they have dropped subscriptions. The data in Table 2, nevertheless, tend to suggest that the number of libraries subscribing to a title is an indication of its probable usefulness for a liberal arts college library.

The 450 titles to which a majority of the libraries subscribe, however, cannot be looked upon as a "basic list" to which every liberal arts college library should subscribe. A total of 4,500 subscriptions would be required to provide all the libraries with these titles. The number of subscriptions actually maintained for these periodicals was 3,399 , or approximately three-fourths of the potential. It certainly cannot be assumed that the 1,101 instances of failure to subscribe or of dropped subscriptions for these 450 periodicals were all mistakes.

\section{Use of the Periodical Bank for Access to Periodicals Owned By Member Libraries}

The second part of this study deals with the requests for photocopies that were filled by the Periodical Bank for the member libraries and the relation of this use to their holdings. This relation is shown in Table 3. This table shows only the requests for periodicals on the holdings lists of member libraries filled by the Periodical Bank between September 1, 1969, and June 30, 1972, a period of time that included three academic years. It does not include requests filled from the Periodical Bank collection, nor from the cooperating libraries for photocopies from titles not on the holdings lists of any of the member libraries.

An examination of Table 3, especially of the last two columns on the right, disposes of the idea that the Periodical Bank could ignore a basic list of periodicals which all the member libraries would hold and for which they would supply all of their readers' needs. The heaviest demand, 78.4 requests per title requested, came for photocopies from titles held by all the libraries, followed by the demand for photocopies from titles held by all but one of the member libraries. The least demand, 12.4 requests per title, was for periodicals owned by only one of the member libraries. Not shown on the table, but lowest of all, was the demand-7.6 requests per title-for periodicals owned only by the Periodical Bank or a cooperating library.

TABLE 2

Number of Subscriptions Maintained and Number Dropped, Classified by the Number of Member Libraries Holding the Title, June 1971

\begin{tabular}{crrrrr}
\hline \hline $\begin{array}{c}\text { Number } \\
\text { Libraries }\end{array}$ & of & \multicolumn{2}{c}{$\begin{array}{c}\text { Number of } \\
\text { Titles }\end{array}$} & Mabscriptions & Toined \\
Dropped & Peral & $\begin{array}{r}\text { Perent } \\
\text { Dropped }\end{array}$ \\
\hline 1 & 1,997 & 1,242 & 755 & 1,997 & 37.8 \\
2 & 524 & 865 & 183 & 1,048 & 17.5 \\
3 & 267 & 659 & 142 & 801 & 17.7 \\
4 & 188 & 676 & 76 & 752 & 10.1 \\
5 & 127 & 570 & 65 & 635 & 10.2 \\
6 & 119 & 661 & 53 & 714 & 8.2 \\
7 & 73 & 492 & 19 & 511 & 3.7 \\
8 & 84 & 636 & 36 & 672 & 5.4 \\
9 & 90 & 783 & 27 & 810 & 3.3 \\
10 & 84 & 827 & 13 & 840 & 1.5 \\
TOTAL & 3,553 & 7,411 & 1,369 & 8,780 & 15.6 \\
\hline
\end{tabular}


TABLE 3

Number of Requests Filled by the Periodical Bank, September 1, 1969, to June 30 , 1972, by Number of Member libraries Holding the Periodical Requested

\begin{tabular}{|c|c|c|c|c|c|c|}
\hline \multirow{2}{*}{$\begin{array}{l}\text { Number of } \\
\text { Libraries } \\
\text { Holding } \\
\text { Title }\end{array}$} & \multicolumn{2}{|c|}{ Number of Titles } & \multirow{2}{*}{$\begin{array}{l}\text { Percent of } \\
\text { Titles Not } \\
\text { Requested }\end{array}$} & \multirow{2}{*}{$\begin{array}{l}\text { Number of } \\
\text { Requests } \\
\text { Filled }\end{array}$} & \multicolumn{2}{|c|}{$\begin{array}{l}\text { Average Number } \\
\text { of Requests }\end{array}$} \\
\hline & Requested & $\begin{array}{l}\text { Not } \\
\text { Requested }\end{array}$ & & & $\begin{array}{l}\text { Per Title } \\
\text { Requested }\end{array}$ & $\begin{array}{l}\text { Per Title } \\
\text { Held }\end{array}$ \\
\hline 1 & 310 & 2,037 & 86.8 & 3,829 & 12.4 & 1.6 \\
\hline 2 & 222 & 402 & 64.4 & 3,283 & 14.8 & 5.3 \\
\hline 3 & 142 & 173 & 54.9 & 3,144 & 22.1 & 10.0 \\
\hline 4 & 130 & 77 & 37.2 & 3,148 & 24.2 & 15.2 \\
\hline 5 & 99 & 46 & 31.7 & 3,777 & 38.2 & 26.0 \\
\hline 6 & 101 & 26 & 20.5 & 3,201 & 31.7 & 25.2 \\
\hline 7 & 69 & 7 & 9.2 & 1,947 & 28.2 & 25.6 \\
\hline 8 & 78 & 11 & 12.4 & 2,326 & 29.8 & 26.1 \\
\hline 9 & 83 & 8 & 8.8 & 4,340 & 52.3 & 47.7 \\
\hline 10 & 77 & 8 & 9.4 & 6,034 & 78.4 & 71.0 \\
\hline TOTAL & $\overline{1,311}$ & 2,795 & $\overline{68.1}$ & $\overrightarrow{35,029}$ & $\overline{26.7}$ & 8.5 \\
\hline
\end{tabular}

The discovery that the demand per title increased directly with the number of libraries holding the periodical called for further investigation. This was done by taking samples of 200 requests from each library and classifying the articles requested under three headings: (1) requests for articles from periodicals not included in the library's list of holdings; (2) requests for periodicals in the library's holdings list but from issues of the periodical shown by the list not to be owned; and (3) requests for periodicals that, according to its list of holdings, should be available in the library. The largest number of requests, 55.7 percent, was for articles from periodicals that the library did not have; and 32.5 percent was for articles from issues not included in the library's holdings. Thus 88.2 percent of the requests were for photocopies of articles that the holdings lists showed were not available on campus. Both of these types of demand were expected, but the importance of the second category reflecting incomplete back files, was certainly underestimated. It was also expected that there would be an occasional situation in which an issue of a periodical would be at the bindery, could not otherwise be located, or had been mutilated. There was also the possibil- ity that screening procedures would not eliminate all requests for photocopies of articles actually available in the requesting library. Whatever the reason, such requests amounted to 11.8 percent of the sample.

The tabulating procedures used made it possible to determine what proportion of all the requests filled were for titles on the requesting library's list of holdings. This gave some indication of the representativeness of the sample. The proportion of all requests which were for titles not on the requesting library's list of holdings was $\mathbf{5 7 . 2}$ percent, as compared with the sample estimate of 55.7 percent. The sampling procedures apparently gave somewhat disproportionate weight to the libraries that made more than the average proportion of their requests for titles on their own holdings lists.

The estimate that over 88 percent of the requests filled were for photocopies from items not in the requesting library's holdings may, at first glance, seem incompatible with the finding that the heaviest demand per title was for photocopies from periodicals found on the holdings lists of all ten libraries. It should be borne in mind, however, that only 77 of the 1,311 titles requested were in the heaviest demand per title 
category and that many of the member libraries' back file holdings of these titles were incomplete.

\section{The Unused Periodicals}

Another significant aspect of Table 3 is the large number of the periodicals on the holdings lists of these libraries from which no requests were filled in three years. A total of 2,795 periodicals, or 68.1 percent of the titles owned, were never requested. The proportion not requested, no less than 86.8 percent of the titles held by only one library, was distinctly greater for periodicals held by a minority of the libraries than for those held by a majority. There are, therefore, three bits of evidence suggesting that the number of libraries holding a title is a useful, if indirect, indication of its probable value in a liberal arts college library. They are the higher proportion of dropped subscriptions among the less commonly held periodicals, the positive relation between the number of requests per title, and the number of libraries holding it, and the predominance of titles never requested among the titles held by only a few libraries. The best measure of the importance of a periodical for a given library is, of course, the amount of use made of it by the library's readers.

If the number of requests filled by the Periodical Bank is an indication of a periodical's usefulness, the large number of periodicals which were never requested raises serious questions about the usefulness of many of the periodicals held by these college libraries. Furthermore, there is no reason to suspect that the periodical selection processes at these libraries are significantly different from those employed by other liberal arts college libraries. The most extreme situation, of course, is that of the 2,037 periodicals owned by only one library and requested by no other library in three academic years.

\section{Intermember Periodical Access}

It may be noted that the ten libraries listed a total of 4,106 different periodicals in their holdings. This may be contrasted with the 1,675 titles held by the Periodical Bank in June 1971. The potential resource for an interlibrary periodical photocopy service represented by these 4,106 titles was recognized when the Periodical Bank was established, and arrangements were made for an interlibrary service paralleling the Periodical Bank service: using the teletypewriter for requests and first class mail for the delivery of photocopies. A summary of the use of this service for one year, July 1,1971 , to June 30,1972 , is given in Table 4 .

If one imagines the hypothetical situation in which the existence of a periodical on a library's list of holdings means that the library is able to satisfy all of its readers' needs for access to the title, and that all the periodicals are equally useful, we would expect no interlibrary requests for titles held by all ten libraries, and approximately nine times as many requests for periodicals owned by only one library as for those held by nine. Table 4 shows that there were 92 ( 18 plus 74 ) requests for titles held by all ten libraries, but there were indeed more requests for uniquely held titles than for those held by nine libraries; 798 (665 plus 133) as compared with 156 (134 plus 22). But there were 2,347 periodicals held by only one library and only 91 titles held by nine libraries. Consequently, there were almost twice as many requests per title owned for the periodicals held by nine libraries as for those held by only one library. This was very different from the 9 to 1 ratio in the opposite direction suggested in the hypothetical situation described above. There is an even greater contrast in the ratio of almost 30 to 1 in favor of the titles held by nine libraries shown by the data in Table 3 for re- 
TABLE 4

Number of Requests Filled by the Interlibrary Periodical Article Photocopy Service July 1, 1971, to June 30, 1972, by Number of Libraries Holding the Trtle

\begin{tabular}{ccccccc}
\hline \hline $\begin{array}{c}\text { Number of } \\
\text { Libraries } \\
\text { Holding } \\
\text { Title }\end{array}$ & \multicolumn{2}{c}{$\begin{array}{c}\text { Number of Titles } \\
\text { Rot } \\
\text { Requested }\end{array}$} & $\begin{array}{c}\text { Percent of } \\
\text { Titles Not } \\
\text { Requested }\end{array}$ & $\begin{array}{c}\text { Number of } \\
\text { Requests } \\
\text { Filled }\end{array}$ & $\begin{array}{c}\text { Average } \\
\text { Pumber of Requests } \\
\text { Requested }\end{array}$ & $\begin{array}{c}\text { Per Title } \\
\text { Held }\end{array}$ \\
\hline 1 & 137 & 1,894 & 93.3 & 665 & 4.9 & 0.3 \\
1 plus $\mathrm{PB}^{\circ}$ & 41 & 275 & 87.0 & 133 & 3.2 & 0.4 \\
2 & 80 & 323 & 80.1 & 321 & 4.0 & 0.8 \\
2 plus $\mathrm{PB}^{\circ}$ & 55 & 166 & 75.1 & 231 & 4.2 & 1.0 \\
3 & 48 & 118 & 71.1 & 127 & 2.6 & 0.8 \\
3 plus $\mathrm{PB}^{\circ}$ & 37 & 112 & 75.2 & 119 & 3.2 & 0.8 \\
4 & 23 & 49 & 68.1 & 156 & 6.8 & 2.2 \\
4 plus $\mathrm{PB}^{\circ}$ & 47 & 88 & 65.2 & 178 & 3.8 & 1.3 \\
5 & 20 & 21 & 51.2 & 106 & 5.3 & 2.6 \\
5 plus $\mathrm{PB}^{\circ}$ & 32 & 72 & 69.2 & 110 & 3.4 & 1.1 \\
6 & 12 & 12 & 50.0 & 33 & 2.8 & 1.4 \\
6 plus $\mathrm{PB}^{\circ}$ & 36 & 67 & 65.0 & 114 & 3.2 & 1.1 \\
7 & 6 & 5 & 45.5 & 19 & 3.2 & 1.7 \\
7 plus $\mathrm{PB}^{\circ}$ & 26 & 39 & 60.0 & 92 & 3.5 & 1.4 \\
8 & 8 & 4 & 33.3 & 68 & 8.5 & 5.7 \\
8 plus $\mathrm{PB}^{\circ}$ & 24 & 53 & 68.8 & 79 & 3.3 & 1.0 \\
9 & 5 & 6 & 54.5 & 22 & 4.4 & 2.0 \\
9 plus $\mathrm{PB}^{\circ}$ & 35 & 45 & 56.2 & 134 & 3.8 & 1.7 \\
10 & 6 & 3 & 33.3 & 18 & 3.0 & 2.0 \\
10 plus $\mathrm{PB}^{\circ}$ & 32 & 44 & 57.9 & 74 & 2.3 & 1.0 \\
TOTAL & & & & & & \\
Not held by PB & 345 & 2,435 & 87.6 & 1,535 & 4.4 & 0.6 \\
Also held by PB & 365 & 961 & 72.5 & 1,264 & 3.5 & 1.0 \\
All titles & 710 & 3,396 & 82.7 & 2,799 & 3.9 & 0.7 \\
\hline
\end{tabular}

- Titles held by the Periodical Bank and the number of member libraries indicated.

quests filled by the Periodical Bank.

The interlibrary loan service was particularly useful for the less generally held periodicals. Of the 2,799 requests filled for member libraries by other member libraries, 798 , or 28.5 percent, were for titles held by only one member library, and 2,146 , or 77.7 percent, were held by five or fewer libraries. Even so, the proportion of the total number of titles held from which other libraries requested photocopies was lower for the less widely held titles. This is particularly true of the periodicals held by only one member library. Only 178 of the 2,347 titles in this category, or 7.6 percent, were requested. The corresponding figure shown in Table 3 for requests to the Periodical Bank was 13.2 percent. Periodicals owned by only one library constituted over 57 percent of the 4,106 different titles held. But 347 of the uniquely held periodicals had ceased publication, and subscriptions to 755 had been dropped. Of these 1,102 dropped or ceased titles, 1,018 were not requested of the Periodical Bank in three years, and 1,061 were not requested in one year through the interlibrary loan service. It seems clear that many of the titles held by only one library were of limited usefulness, especially those periodicals that had ceased publication and those to which subscriptions had been dropped.

Table 4 shows separately the data for titles held by member libraries and those held also by the Periodical Bank. More than half of the periodicals requested were also held by the bank, but the number of requests for these periodicals was less than for those not owned by the bank. There are probably a number of different situations in 
which another library rather than the bank is asked for a photocopy. Among them is the greater proximity of a neighboring college, and the fact that during 1971-1972-but not subsequently-the member libraries were charged twenty cents per exposure for photocopies made at cooperating libraries, but only ten cents per exposure for photocopies made from the holdings of the Periodical Bank or a member library. If the Periodical Bank was unable to fill a request from its holdings, it notified the requesting library, which then might turn to the interlibrary photocopy service with the request.
Of the 4,106 different periodicals owned by the member libraries, 2,795, or 68.1 percent, were never requested in one year from another member library. Measured by these tests, it appears that the member libraries are spending thousands of dollars each year on periodicals of doubtful utility. The real test, of course, is the actual use made by the libraries' readers. The savings promised by the elimination of unused periodicals justifies substantial efforts at every liberal arts college library to discover just how much use is being made of every title on its list of periodical holdings. 